\title{
Impact of Karakoram Highway on the Education and Health Development of Gilgit- Baltistan, Pakistan
}

\author{
Salman Anwar ${ }^{a}$, Nouman Khan ${ }^{\text {b }}$, Muhammad Mumtaz ${ }^{\text {c }}$ \\ ${ }^{a}$ Assistant Professor, Government Superior Science College, Peshawar, Pakistan \\ ${ }^{\mathrm{B}}$ Lecturer, Department of History and Politics, University of Haripur, Pakistan \\ ${ }^{\mathrm{c}}$ Assistant Professor, Department of Management Sciences, the University of Haripur, Pakistan, \\ Email: mumtaz86@hotmail.com
}

\begin{tabular}{|c|c|}
\hline ARTICLE DETAILS & ABSTRACT \\
\hline History: & \multirow{8}{*}{$\begin{array}{l}\text { Education is the soul of a society. It is a long term investment by a state } \\
\text { to develop its human capital. Those countries which invested heavily in } \\
\text { human development are reaping the benefits. Education and health as } \\
\text { indicators of human development are of utmost importance. Gilgit- } \\
\text { Baltistan (GB) in the extreme north of Pakistan is a mountainous area. } \\
\text { Before the construction of Karakoram Highway (KKH), their status of } \\
\text { education and health was extremely miserable. Only } 3 \text { middle and } 80 \\
\text { primary schools were available in the entire area of Gilgit-Baltistan. } \\
\text { Similarly, } 2 \text { hospitals and } 10 \text { small dispensaries were available in the } \\
\text { health sector. Therefore, this study is an effort to evaluate the impact of } \\
\text { KKH on education and health development of Gilgit-Baltistan. Results } \\
\text { show a significant change and development, especially in the education } \\
\text { sector. However, in the health sector, there is an intense need for more } \\
\text { investment. As the area of Gilgit-Baltistan is vast and scattered, the } \\
\text { people face difficulties in reaching the health care centers. }\end{array}$} \\
\hline Accepted 30 Nov 2020 & \\
\hline Available Online 31 Dec 2020 & \\
\hline Keyn & \\
\hline $\begin{array}{l}\text { KKH, Gilgit-Baltistan, Education, } \\
\text { Heath, Human Development, } \\
\text { Schools And Hospitals }\end{array}$ & \\
\hline JEL & \\
\hline N15, I21, & \\
\hline DOI: & \\
\hline
\end{tabular}

(C) 2020 The authors. Published by SPCRD Global Publishing. This is an open access article under the Creative Commons Attribution-

NonCommercial 4.0

Corresponding author's email address: mumtaz86@hotmail.com

\section{Introduction}

This paper attempts to assess the impacts of Karakoram highway (KKH) on education and health sectors of Gilgit-Baltistan. The study was undertaken in Gilgit-Baltistan area of Pakistan. GilgitBaltistan covers an area about $72,496 \mathrm{~km}^{2}$ with three divisions and ten districts namely, Gilgit, Diamer, Hunza, Nagar, Ghanche, Ghizer, Skardu, Shiger, Kharmang and Astore. The area holds great importance due to its geographical location, as it connects Central Asia and China to Pakistan. The people of this area found it difficult to travel to the other provinces of Pakistan until the construction of KKH. 


\section{Review of Economics and Development Studies, Vol. 6 (4) 2020, 821-832}

During the pre-independence era, no attention was given towards the educational need of the area. There were only few schools only for males, until 1947 (Dani, 2001). The students who were willing to carry on their studies had to go to Kashmir, Deoband or Aligarh.

The Government of Pakistan paid much attention to provide educational facilities to this area, however due to lake of means of communication, absence of approach road and other impediments, the task was become extremely hard. At that time because of acute deficiency of literate persons, the GilgitBaltistan Administration was bound to hire educated persons from other provinces by giving them extra benefits (Benz, 2013). In the beginning public education was directly under control of the Political Agent. During the years 1976-78 Directorate of Education was established. In 1979 the powers of running the education department of GB were given to the ministry of Kashmir Affairs (Hussain, 2016). From 2009 onward, Gilgit-Baltistan has its own, Directorate of Education.

The British Indian authorities took no interest in providing basic health facilities to the people of these remote areas. At the time of independence there were only two hospitals and 10 small dispensaries for the whole area (Ali, 2010). The Government of Pakistan tried its level best to provide basic health facilities to the area, but the absence of a smooth highway was a main hurdle. The Construction of Karakoram Highway not only linked this gorgeous area to other provinces but also gave a sigh of relief to the people, as for as health facilities are concerned (Sokefeld, 2014).

The objective of this study was to analyse the change in education and health sector of the study area after the construction of KKH. The analysis revealed that a positive change has been occurred as for education is concerned. However health sector lags behind due to harsh mountainous terrain, scattered population and limited resources.

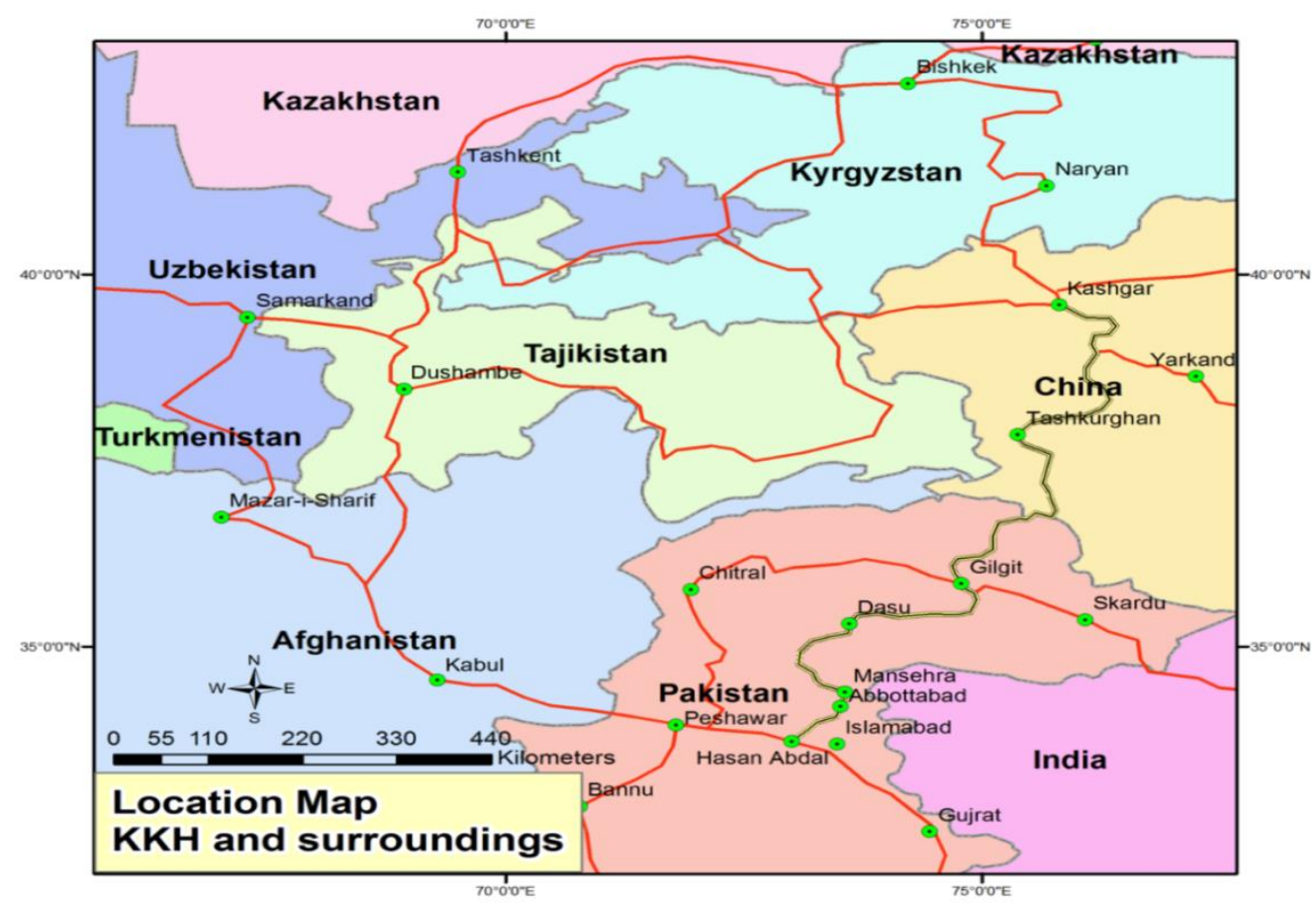

Figure 1, Location map of KKH \& Gilgit-Baltistan modified after Said, 2005

\section{Methods and Material}

\subsection{Study Area}

Gilgit-Baltistan spreads over 72,496 square kilometers. The population is estimated as 1.48 million according to census 2017. People live in small settlements scattered in mountains and valleys. 


\section{Review of Economics and Development Studies, Vol. 6 (4) 2020, 821-832}

Villages consist of limited households with an average family size of nine members. The density of population is 8 persons /sq. $\mathrm{km}$. The literacy rate is $33 \%$ (44\% male, $21 \%$ female) (GOGB \& AKESP, 2008).

\subsection{Methodology}

Mix methodology approach was used because the data presented in this paper is both quantitative and qualitative in nature. Theoretical framework was derived from the growth pole theory presented by Francois Perroux. He explains that socio-economic growth is not even, but it has different level of intensity in different places, points or poles. The development spreads from these poles and the outcome is different in every region. The data was collected during three field visits of Gilgit-Baltistan in 2016, 2017 and 2018. The authors' conducted interviews with officials, students, teachers, and principals of different schools and colleges of Gilgit-Baltistan. The Education and Health Departments of Gilgit-Baltistan also provided some valuable statistical data. Research papers mentioned in the reference section also helped to create an insight for this study.

\section{Results and Discussions}

\subsection{Educational progress of Gilgit-Baltistan}

The analysis reveals that harsh mountainous terrain and long distances in the study area has directly affected the educational development. Small villages with no link roads make it difficult for government to build schools in every village with adequate facilities (Cook \& Butz, 2011). The private sector also has no attraction in such areas. The socio-cultural environment is also one of a hurdle in promoting education especially for females. The federal government, Agha khan education services of Pakistan, National education foundation and private sector has contributed a lot in education sector (GOP, 2008). At Primary, middle and high levels every two to three villages is having a public sector schools, while the number of colleges are also increasing. Before the construction of KKH the people of study area were totally ignored regarding education. All the development in education sector we and the inhabitants of the area is witnessing was only possible in the last 30 to 35 years after the inauguration of $\mathrm{KKH}$.

Education is a long term investment for socio-economic development of a society. Institutions require a lot of time to build up, strengthen and deliver up to the mark. The world famous education institutions delivered after centuries of services in educating their youth and research activities. Expecting high quality and deliverance at this stage from a transitional society is not good (Benz, 2016). As mentioned above a lot has been achieved during the last 35 years but still the sector requires more attention to strengthen and deliver for socio-economic development of the area. Now it's high time for the authorities to facilitate the society with qualified staff and quality education after infrastructural development. A big responsibility also lies on the shoulders of teachers, parents and students to take the responsibility and develop their society.

The analysis reveals that development of education sector in the study area requires three main initiatives. To insure education access for all the people, this objective have almost been achieved almost at primary to high levels. Although there are hurdles regarding walks from home schools but it is obvious due to the geography of the area. To insure the quality of education in the study area, it will take some time as the institutions are relatively new and not fully equipped. Quality education also requires high qualified teachers, trainers and inducements. And last but not the least to produce skillful labor which requires technical education (Sokefeld, 2005). The progress of educational development of the study area is discussed in detail in this chapter. 
Review of Economics and Development Studies, Vol. 6 (4) 2020, 821-832

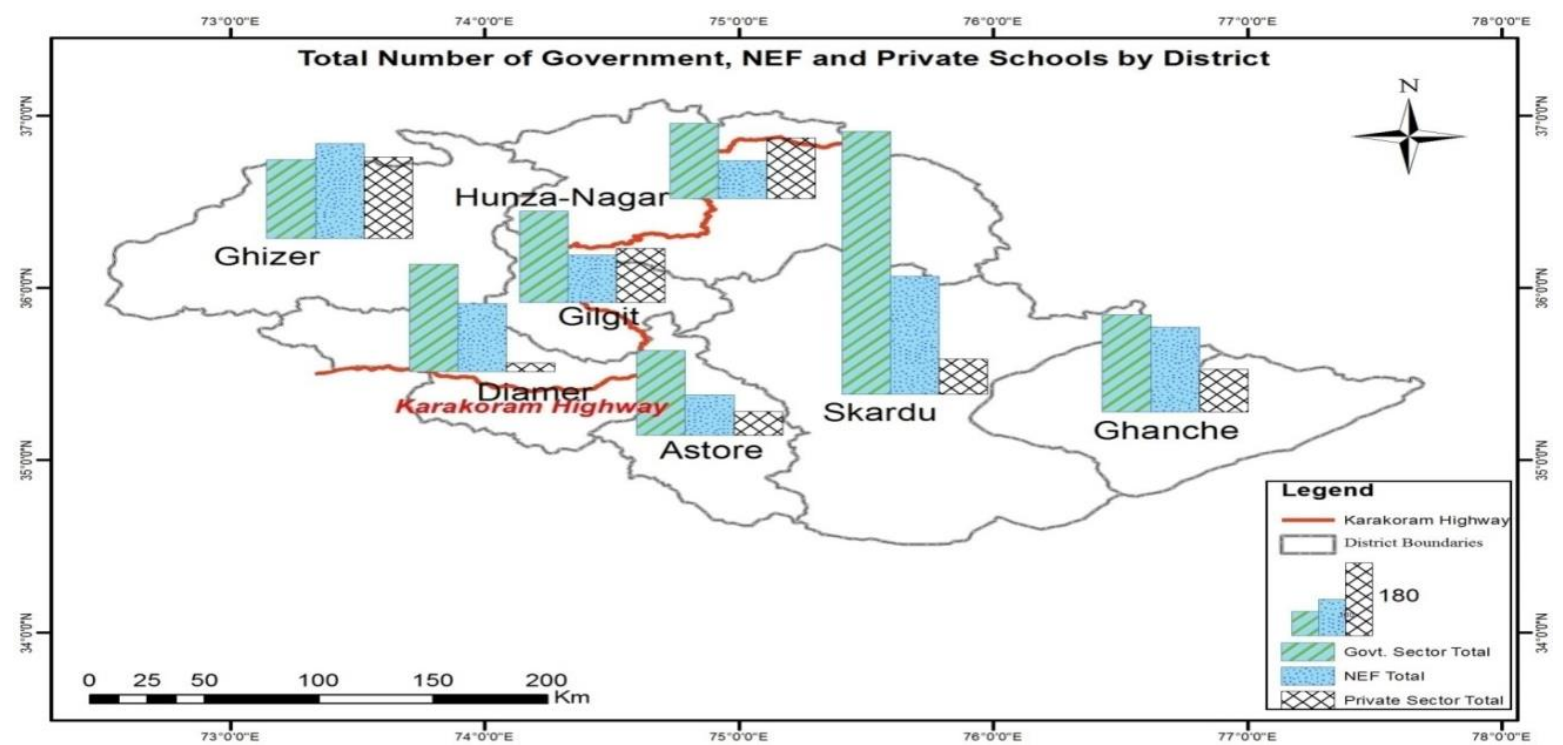

Figure 2, Number of Government, Semi-Government and Private Schools till 2016

Gilgit-Baltistan has shown better results during the last thirty five years. The literacy rate of the study area in 1981 was only 14 percent which is now 52 percent (GOGB, 2005). It is pertinent to note here that literacy rate of females have risen up to 38 percent which is a very encouraging sign (AKRSP, 2012). The gains in literacy rate is attributed to accessibility, specially $\mathrm{KKH}$ which has transformed the whole region of Gilgit-Baltistan from a remote, primitive, deprived and ignored society to a socioeconomic developed society. The role of some non-governmental organizations like Agha Khan cannot be ignored as well but anecdotal evidences proves that this development occurred only after the inception of $\mathrm{KKH}$.

The data shows that during 2012-2013 almost 6o\% percent students of Gilgit-Baltistan were enrolled in Government run institutions, whereas enrollment in private schools were $22 \%$ and only $18 \%$ students were enrolled in schools run by National Education Foundation (AKRSP, 2011). This clearly show the dominant share of Government schools. The analysis further reveals that the number of boys schools are more than the girls that is why the ratio of male literacy is more than the female, also shown in Figure 3.

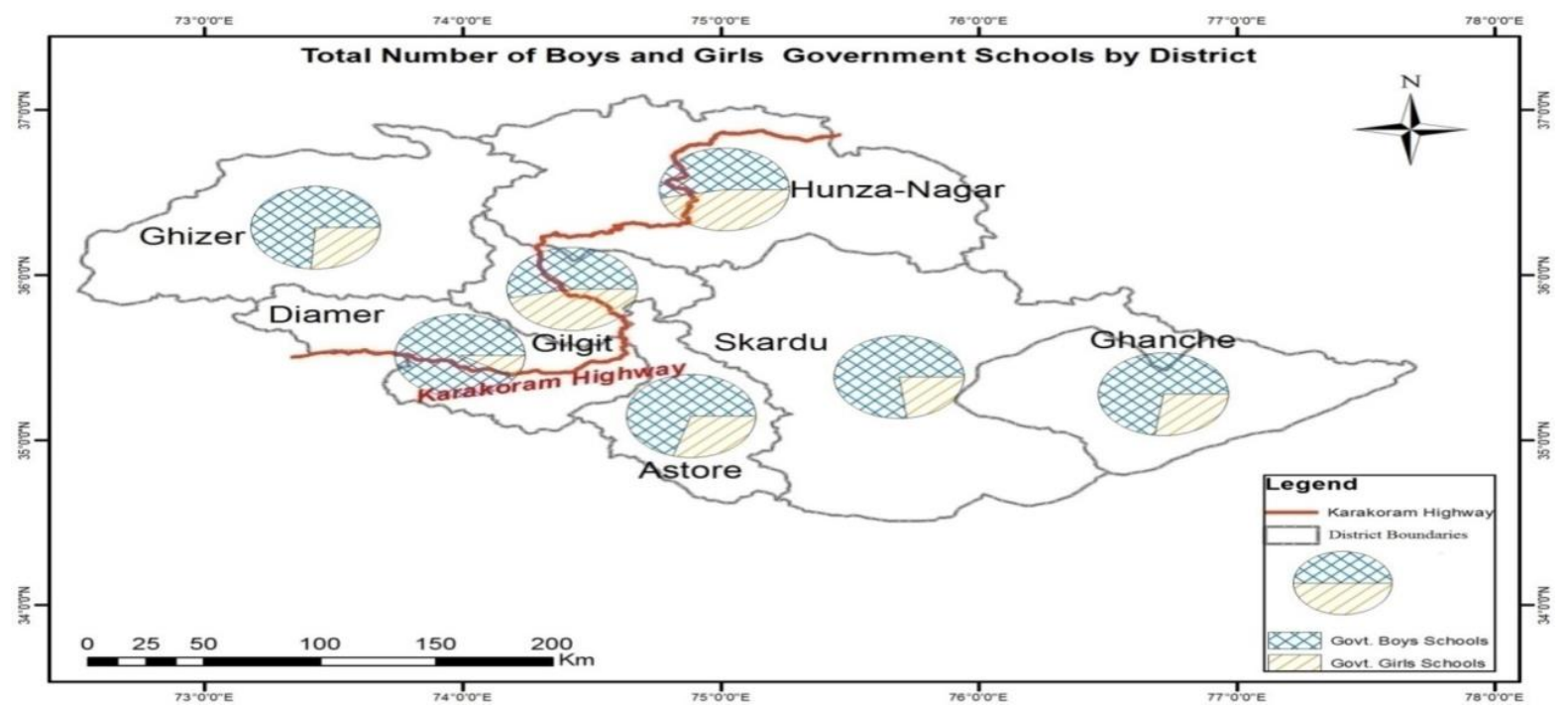

Figure 3, Gilgit Baltistan, Ratio of male and female schools,

Source, Directorate of Education, Gilgit-Baltistan, 2016-17. 
In the study area, more than fifty percent of the educational institutions are constructed and run by the government. Figure 4 shows a greater share of government recruited teachers in schools and colleges. It clearly indicates that the share of public sector investment is very high.

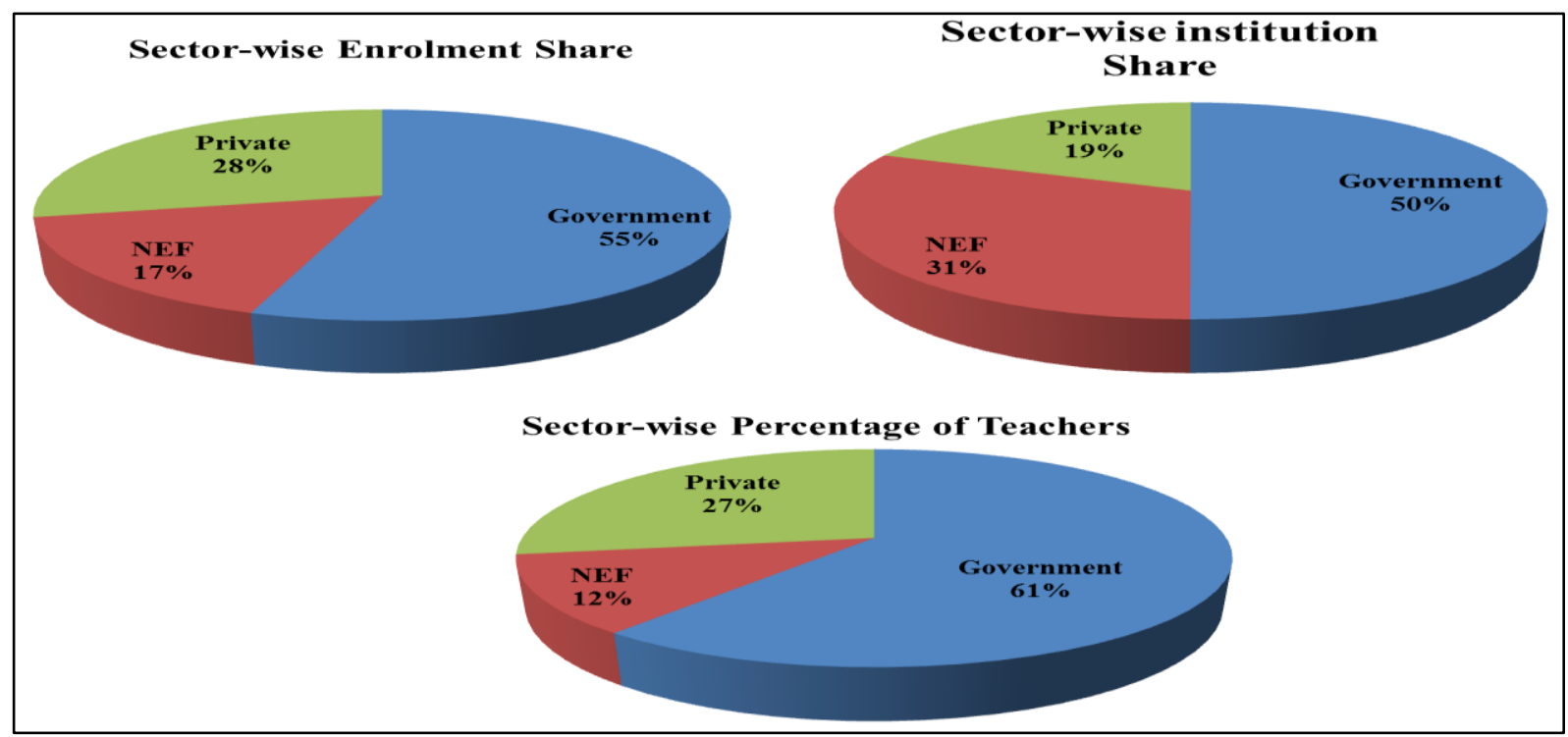

Figure 4, Gilgit-Baltistan, Share of Government, National Education Foundation and Private Sector, 2015-16.

Source; Directorate of Education, Gilgit-Baltistan, 2016.

In the study area ratio of female education has rapidly increased during the last thirty five years shown in Figure 5. It is a very encouraging sign because educating a girl is educating a family. That is why not only in Gilgit-Baltistan but throughout Pakistan female literacy rate is increasing day by day. Looking towards the interest of females in education sector it is hoped that the gap between male and female literacy would be overcome in the near future.

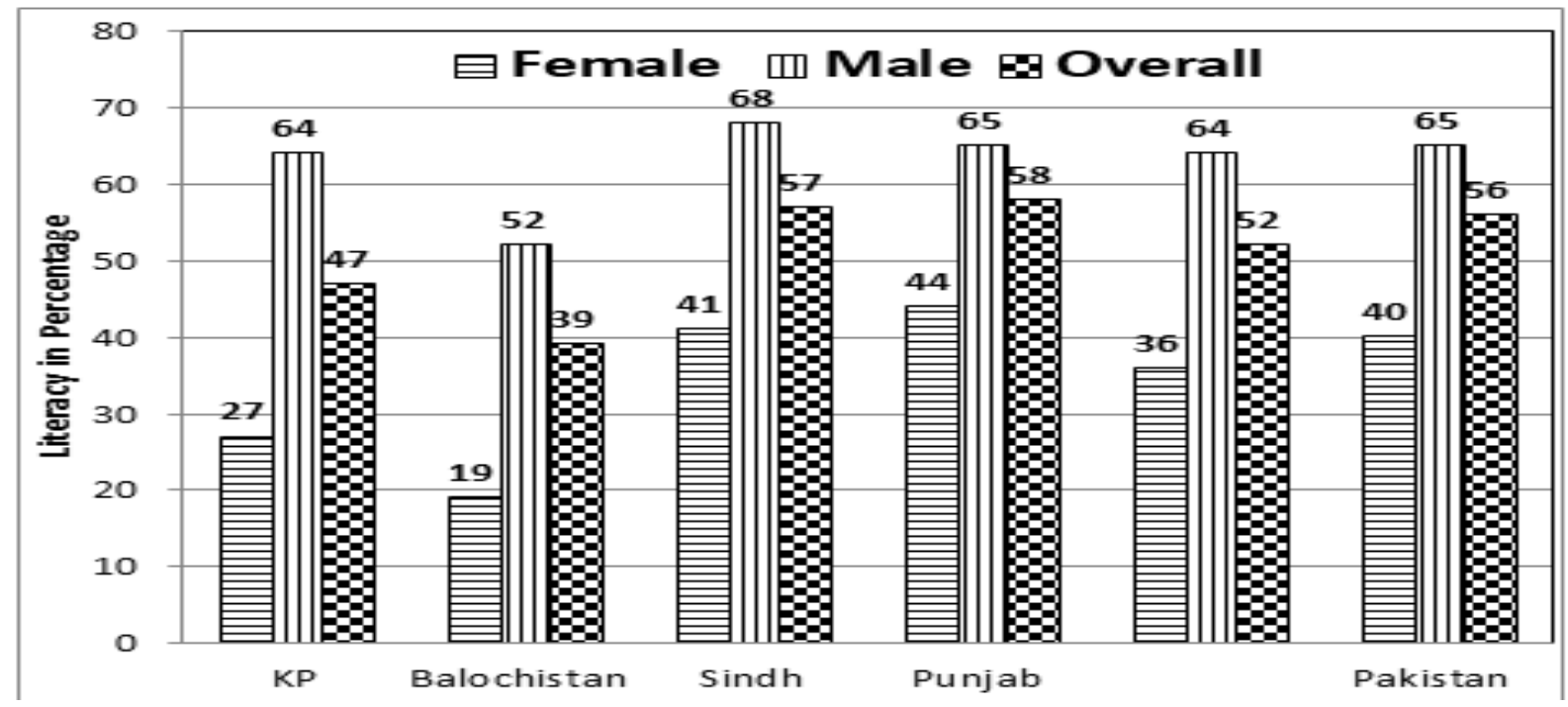

Figure 5, Gilgit-Baltistan, Gender wise literacy ratio as compare to other provinces, 2012-2013. Source; Directorate of Education, Gilgit-Baltistan, 2016.

\subsubsection{Enrollment ratio in high school and college level}

The analysis reveals that the ratio of enrollment of students at intermediate and degree level is 


\section{Review of Economics and Development Studies, Vol. 6 (4) 2020, 821-832}

low as compared to schools. The details given below in the (Figure 6) shows a full picture of the student's enrollments. If we look at the number of colleges it is twenty one in the whole region with only four colleges for girls. When I asked one of a student of Government Degree College for boys, Gilgit why he quit his education at degree level he answered, there is only one college in our district and I could not afford to go to college daily from my village far away from the college. Likewise there is only one university in the study area which cannot absorb the students from the whole region (World Bank, 2011).

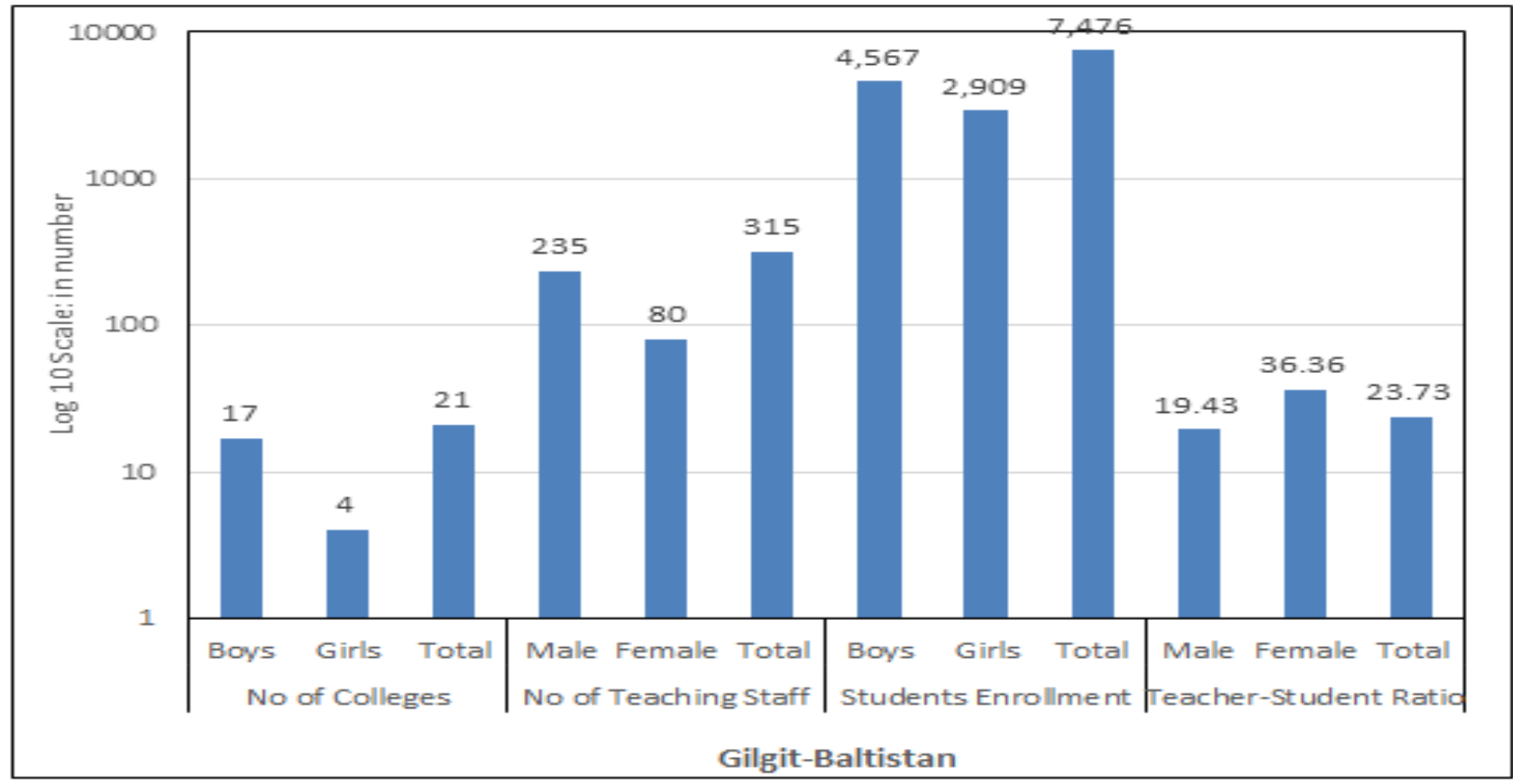

Figure 6 Gilgit-Baltistan, numbers of Government Colleges, teaching staff, student's enrollment and Students-Teachers Ratio, 2012-13, after GOGB, 2013

The Federal government of Pakistan in 2002 established Karakoram International University at Gilgit. Establishment of this University was a blessing for the pupils of Gilgit-Baltistan. The enrollment ration in the university is high and encouraging the authorities to invest more in its development. KIU offers BS 4 years Programme in various fields; master, M.Phil and PhD level Programme have also been initiated with the help of Higher Education Commission of Pakistan. More than three thousand students both male and female are enrolled currently in different departments in this university (KIU, 2012). However like all other departments KIU is also facing some infrastructural deficiencies i.e students' hostel for (male). There is only one female hostel on the university campus.

It is a positive step towards higher education in the study area as it was observed during the field survey during the focused group discussion with the students. Another campus of KIU is founded at Skardu facilitating the students for higher education at their doorstep. The KIU is moving in right direction according to the needs and requirements of the local population. In the future more campuses will be built in other districts of Gilgit-Baltistan.

\section{Impact of Karakoram Highway on Health}

The populace of Gilgit-Baltistan is scattered in the rocky landscape. The difficulty of infrastructure development and access for the poor people are the main hurdles which is a challenge for the government. Again the significance of accessibility for the study area is evident. Before the inception 


\section{Review of Economics and Development Studies, Vol. 6 (4) 2020, 821-832}

of $\mathrm{KKH}$ there was no hospital in the whole area and the inhabitants of Gilgit-Baltistan were at the mercy of Allah. Centuries old traditional health care methods were in practice. In most of the villages of the study area the traditional way of dealing the birth delivery cases is still in practice which is risky and leads to high mortality rates.

In the study area providing basic and advanced health facilities to the whole population is a challenge for the Government. This is not only the issue of Gilgit-Baltistan but almost all provinces are facing the same problems. The problems are further deteriorated by the rocky terrain and inhospitable environment. In these circumstances it is very difficult for the poor people to reach the health care units or the hospital. Although the government is striving hard to provide health facilities to every single person but limited resources is an obstacle. In health sector infrastructure development is not a big issue but its operation is a daunting task. Deficiency of doctors, nurses, medical practitioners and equipment's is another challenge. The following table and figure shows a detail picture of health facilities in the study area. The total number of health facilities units is about five hundred but most of them are small units or non-governmental dispensaries (Halvorson, 2003). Only five district hospitals with limited capacity is not a positive sign. The number of basic health units (BHU) and Regional health centers (RHC) is also very low. But the comparative data of the health facilities before and after $\mathrm{KKH}$ period shows completely a different picture which is obvious in the figure 7 below.

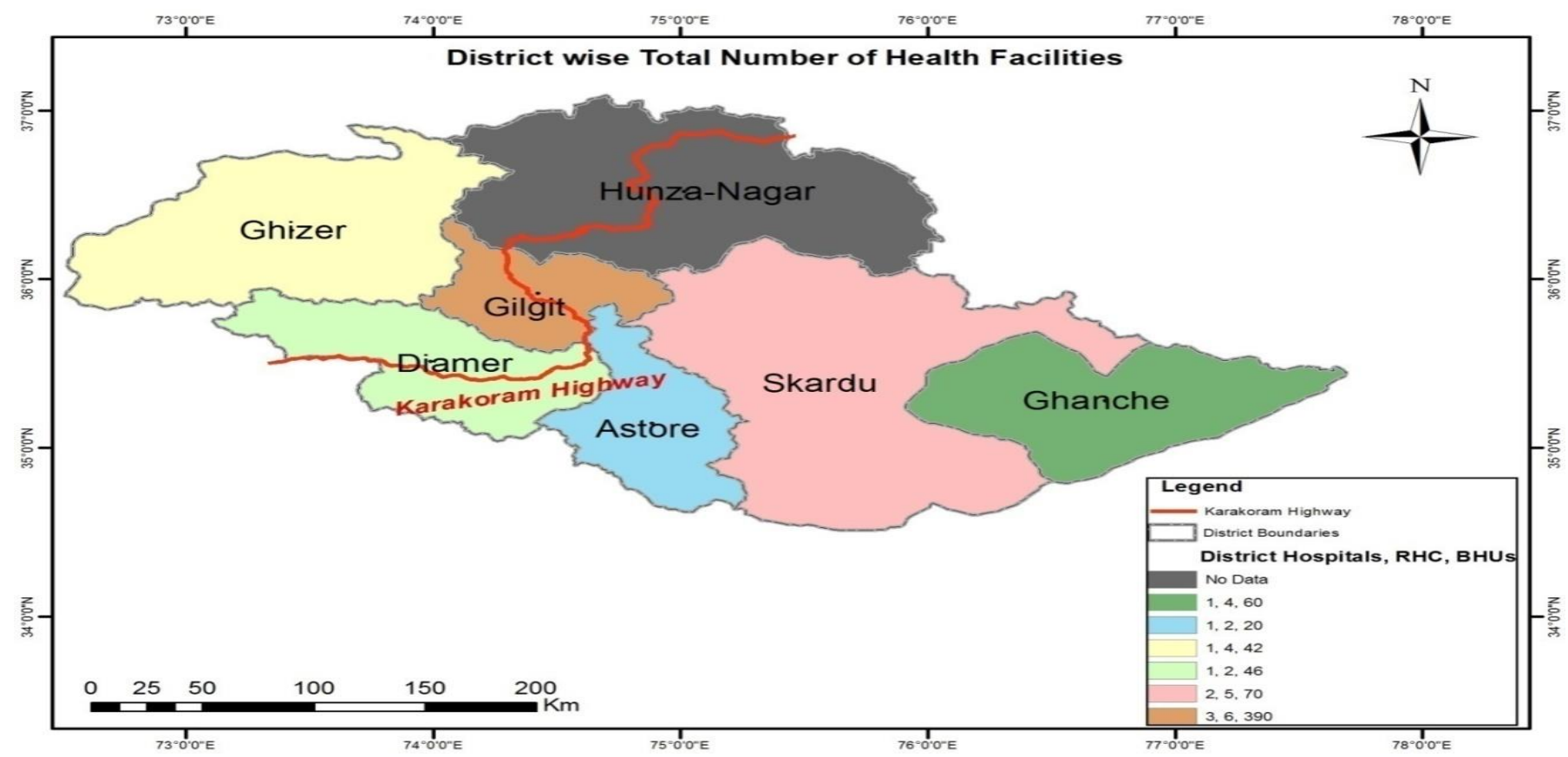

Figure 7, Gilgit-Baltistan, Health Institutions

\subsection{Mother and Children Health Facilities}

In the study area mother and child health care situation is alarming. It is a very important segment of our society. The future of society depends upon a good health of both mother and child. A healthy mother would give birth to a healthy child and a healthy child is the future asset of the society. More efforts are needed to strengthen the health facilities for mother and children in the study area shown in Table 4. The following table shows a detail of Mother and child care facilities. 
Review of Economics and Development Studies, Vol. 6 (4) 2020, 821-832

Table 4 MCH Outputs at Health Facilities

\begin{tabular}{|c|c|c|}
\hline Indicators & Gilgit-Baltistan (\%) & Pakistan (\%) \\
\hline Delivery Record & $\mathbf{2 6}$ & - \\
\hline Monitoring Child Health & 5 & 25 \\
\hline Women's visiting gynecology clinics & 43 & 24 \\
\hline Births at Hospitals or units & $\mathbf{2 2}$ & $\mathbf{2 5}$ \\
\hline Family Planning facilities & 19 & 48 \\
\hline Average visitors to Family Planning & $\mathbf{2 6}$ & $\mathbf{2 2}$ \\
\hline
\end{tabular}

Source: Directorate of Health, Gilgit-Baltistan, 2013

The analysis reveals that infant mortality rate in the study area is high as compare to other provinces of Pakistan. Inhospitable and tough environment on one side lack of basic health facilities and poverty also contribute to this great loss. One hundred twenty five per one thousand in 1998 and seventy eight per one thousand in 2012 is not a positive sign (GOP, 2005). Most of the deaths occur during the first two months after birth. It is very high as compare to the developing nations in the world i.e. fifteen per one thousand. As mentioned above this issue should be addressed on war footings. Again it is pertinent to note here the significance of accessibility that how much it is important for the development of a society.

Infant mortality is directly related to Mother mortality rates because most of the mothers dies during delivery cases. In the study area the ratio is much high then the other parts of the country. According to 1998 census six hundred per one lakh mothers dies during delivery (GOP, 2001). It can be decreased by giving more facilities to the poor people of Gilgit-Baltistan at their doorstep. Lack of education and awareness about the complications of pregnancy, poverty and non-availability of basic health facilities all contribute to this heavy loss. Again preventing this is a challenge not only for the government of Gilgit-Baltistan but for the federal government too. More attention is needed to prevent this heavy losses which is also leading to affect the sex ratio of the study area i.e. one hundred and ten males for hundred females.

The family planning program in the study area was initiated in 2001 to facilitate the local community of Gilgit-Baltistan. The number of family planning centers has now reached to fifty. In remote villages the same work is done by the lady health visitors (LHV) and lady health workers (LHW). Although these LHV and LHW are working across the country and doing a good job but it requires a proper planning and monitoring system to further enhance their capacity. The government can provide more basic health facilities especially during and after pregnancy period with the help of these mobile workers. The analysis further reveals that more than seventy five percent family's needs family planning services but only twenty five percent are getting until now. The remaining fifty percent are deprived due to non-availability of the medicines or in accessibility (Halvorson, 2003).

In the study area the fertility ratio is higher than the national level i.e. 4.6 ratio 4.1. The ratio of fertility was recorded as 5.4 during 1998 census but due to the initiatives and facilitation of family planning it has shown a little bit declines in the recent surveys (GOP, 2001). The geography of the study area and its population have inverse proportion as only 1.3 million people living in the vast area of 72 , $496 \mathrm{sq}$. km. the family planning programme does not means to stop the ratio of population but it has multiple objectives, primarily to save the life of both the mother and child and to create awareness among the families to have a gap between births. 


\section{Review of Economics and Development Studies, Vol. 6 (4) 2020, 821-832}

\subsection{Starvation and Nutrient deficiency}

The analysis reveals that before the construction of KKH most of the poor population was facing starvation in the winter season. It was only after the inception of $\mathrm{KKH}$ that people of the area took a sigh of relief and they are now getting every kind of food items at their door step. The deficiency of iodine is also reduced by promoting iodized salt in the area. These nutrient deficiencies lead to different kind of diseases in the children. The following figure show a detail picture of the study area with comparison to the other provinces of Pakistan. It is essential not only for government but also for the society to provide good food to their children's because they are the future asset of the society.

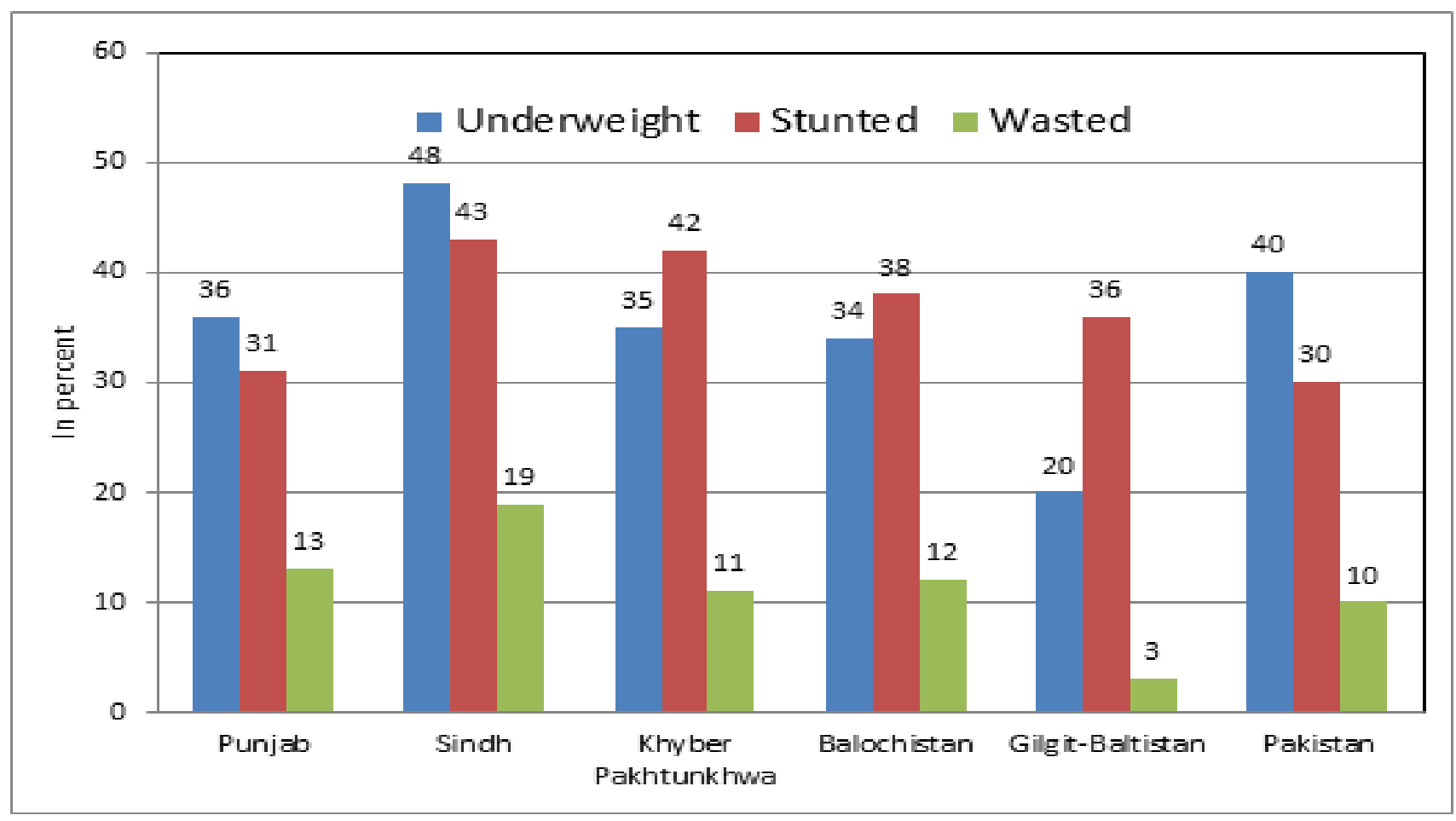

Figure 8, Child Malnutrition ratio in Gilgit-Baltistan as compare to other provinces, 2012-13.

\subsection{Restraints in Health Sector}

It was observed that the local people are still facing a lot of difficulties in health sector. Although a positive change is observed after the inception of $\mathrm{KKH}$ but still link roads connecting the remote areas to $\mathrm{KKH}$ are not good enough for smooth driving (AKHSP, 2000). The people have to cover a lot of distances to reach district headquarter hospitals within the region. In many cases the patients could not reach to the hospital alive and die on the way. The constraints in health sector are discussed in detail in the following paragraphs.

\subsection{Accessibility and Health facilities}

Accessibility has a direct relationship with the socio-economic development of any society. Without accessibility any kind of development is useless. $\mathrm{KKH}$ was a blessing for the closed and primitive society of Gilgit-Baltistan. Providing health facilities in the harsh mountainous society is a gigantic task. The accessibility problems in the villages also make it difficult for the administration, health workers and even the patients to reach and take benefits. The study area has a dispersed population mostly in villages making it difficult for government and doctors to reach to each nuke and corner. A small project like polio vaccination is also costing very high for government in the remote villages (Sokefeld, 2014). In order to get medical facilities like surgeries, deliveries and chronic cases the people of far flung area have to travel and take appointments in advance. It is a challenging situation for both the government of Gilgit-Baltistan and the inhabitants of the area. This problem can only be 


\section{Review of Economics and Development Studies, Vol. 6 (4) 2020, 821-832}

solved either by providing the facilities at the doorstep which is not impossible but difficult in the current situation or by improving the quality of link roads

It was also observed during a field survey that even the government has tried its best to build a small dispensary or health unit the problem of recruiting a doctor or dispenser arises. People prefer to serve in urban areas as it is the case all over the country. A strict policy is needed in this regard to hire the services and compel them to serve at their appointed places with some incentives like extra payment and providing home facilities.

Table 5, Hospitals, Regional and Basic Health Centers

\begin{tabular}{|c|c|c|c|c|c|c|c|}
\hline $\begin{array}{c}\text { Type of Health } \\
\text { Institution }\end{array}$ & Gilgit & Skardu & Diamer & Ghizer & Ghanche & Astore & Total \\
\hline District Hospitals & 3 & 2 & 1 & 1 & 1 & 1 & 9 \\
\hline RHC/civil hospitals & 6 & 5 & 2 & 4 & 4 & 2 & 23 \\
\hline BHUs/dispensaries & 390 & 70 & 46 & 42 & 60 & 20 & 628 \\
\hline
\end{tabular}

Sources: Directorate of Health, 2012-13

As discussed above the accessibility to health centers is the main problem. Covering area of these health centers is very vast as compare to other provinces of Pakistan. In other provinces the covering area is twenty two square kilometers while in the study area it is hundreds and thousands of kilometers making it difficult for the people to reach in time. One of the benefits of the KKH is the growing buildup areas in the districts along this gigantic highway (GOGB, 2009 ). Gilgit has the largest density and more health centers in public as well as private sector. It is therefore, necessary to focus more on quality and providing facilities at every center because health is a primary objective of every welfare state.

\subsubsection{Limited Availability of Skilled Staff}

The study area has also limited skilled man power. The reason for this deficiency is obvious as all professionals and skilled labor prefer to work in cities. In health sector this deficiency is more evident because of the limited availability of doctors as well as nurses. An average of two doctors per ten thousand people is a very big difference including all the hospitals and dispensaries. For more than three hundred and fifty health centers only one hundred and thirty eight doctors are available (AKRSP, 2012). This issue needs serious consideration on behalf of provincial as well as federal government to recruit more doctors on priority basis by giving them special salary packages.

It was also observed during the field survey and interviews that the local qualified people prefer to work in other provinces of Pakistan. As they deem it necessary for their future career because there was no attraction until inception of China Pakistan economic corridor. Lying on the border of China the future of the study area is very bright and now the educated people are coming back to their native region for better opportunities. Still the area is severely lacking skillful female workers, to some extent Agha Khan Rural Support Programme has recruited female workers in every sector but not sufficient enough to fill the gap of required workers (AKRSP, 2011). Female doctors are very few in number, only lady health visitors are working more efficiently everywhere in Gilgit-Baltistan. 


\section{Review of Economics and Development Studies, Vol. 6 (4) 2020, 821-832}

\section{Conclusion}

To conclude the paper, it was found that the construction of Karakoram highway has left very positive impacts on both education and health sectors in Gilgit-Baltistan. The local people took a sigh of relief as their children are now going to schools, colleges and universities. The construction of KKH has brought them in contact with other cities of the country. They are now traveling easily not only for education and health facilities but for other socio-economic activities as well.

The analysis reveals that the study area has enormous potential of development in education sector. The statistics mentioned in this paper shows a very positive picture of educational development in the area. In a very short period much has been achieved but still requires more efforts as education is an endless journey. During the last three decades focus was on infrastructural development which is done quite remarkably. Now the circumstances suggest that human resource should be developed in the area to provide social services. For this purpose it is necessary to give more trainings and employments to the local educated people. After 2009 Gilgit-Baltistan self-governance act a positive change was observed in all sectors. Establishment of new departments has opened the doors of a lot of opportunities for the qualified local young generation.

However the health sector needs much attention, as it lags behind as for as basic health facilities are concerned. Human resource development is the key issue of heath sector as the ratio of doctors is very low and only LHV are working efficiently also filling the gap of doctors. Human resource development can only be improved in health sector by giving more incentives and job securities to doctors as well nurses. The ratio of big hospitals is also very low which needs to be at least two in every district in the current situation.

\section{Acknowledgments}

This Research paper is part of PhD thesis of principal author submitted to the Area Study Centre, University of Peshawar.

\section{References}

AKRSP. 2011. Six-Monthly Progress Report, June-December 2010. Emergency Field Office Gulmit: Aga Khan Foundation AKRSP.

AKRSP. 2012. Monitoring, Evaluation, and Research Section Annual Report 2010. Gilgit: Aga Khan Foundation AKRSP.

Ali, Nosheen. 2010. Books Vs Bombs? Humanitarian development and the narrative of terror in Northern Pakistan. Third World Quarterly 31 (4):541-559

Benz, Andreas. 2013. Education and Development in the Karakorum: Educational Expansion and Its Impacts in Gilgit-Baltistan, Pakistan. Erdkunde, 67(2).

Benz, Andreas.2016. Framing Modernization interventions: Reassessing the role of Migration and translocality in sustainable mountain development in Gilgit-Baltistan, Pakistan. Mountain Research and Development 36(2): 141-152

Cook, Nancy and Butz, David. 2011. Narratives of Accessibility and Social Change in Shimshal, Northern Pakistan. Mountain Research and Development, 31(1).

Dani, A.H. 2001. History of Northern Areas of Pakistan (upto 2000 AD). Lahore: Sang-e-Meel Publishers.PP.283.

GOGB and AKESP.2008. Northern Areas education Strategy 2008-2025. Department of Education, Gilgit: Aga Khan Foundation.

GOGB. 2009. Annual School Statistical Report (2008-09). Department of Education, Gilgit.

GOGB.2005. Medium-Term Development Framework (2005-10) for the Northern Areas. Planning 
and Development Department, Northern Areas, Gilgit.

GOP. 2001. District census report of Baltistan 1998. Population Census Organization, Statistics Division, Islamabad.

GOP. 2005. Pakistan Social and Living Standard Measurement Survey (PSLM) 2004-05, Federal Bureau of Statistics.

GOP. 2008. Pakistan Demographic and Health Survey (PDHS) 2007, National Institute of Population Studies, Islamabad.

Halvorson, Sarah. J. 2003. A Geography of Children's Vulnerability: Gender, Household resources, and Water-related Disease Hazard in Northern Pakistan. The Professional Geographer, $55(2)$.

Halvorson,Sarah J.2003. 'Placing' health risks in the Karakoram: Local perceptions of disease, dependency, and social change in northern Pakistan. Mountain Research and Development 23 (3):271-277

Hussain,Shafqat.2016. Remoteness and modernity. Transformation and continuity in Northern Pakistan. New Haven: Yale University Press.

Karakorum International University. About Karakoram International University: Gilgit. http://www.kiu.edu.pk/about_kiu.html ,18.o9.2012.

Sokefeld, Martin.2005. From colonialism to postcolonial Colonialism. Changing modes of domination in the Northern Areas of Pakistan. The Journal of Asian Studies 64 (4): 939-973

Sokefeld, Martin. 2014. Anthropology of Gilgit-Baltistan: Introduction. Ethnoscripts, 16(1).

World Bank. 2011. Gilgit Baltistan Economic Report, Broadening the Transformation, GilgitBaltistan. 